\title{
Para o estudo das aves em Portugal (séculos XIII-XVI): conflitos e proteção, segundo o testemunho das fontes jurídicas e os livros de viagens
}

\section{Para el estudio de las aves en Portugal (siglos XIII-XVI): conflictos y protección, según el testigo de las fuentes jurídicas y los libros de viajes}

\section{A contribution to the study of birds in Portugal $\left(13^{\text {th }}-16^{\text {th }}\right.$ Centuries): conflicts and protection, according to the testimony of the legal documents and travel books}

\author{
Maria Alice da Silveira TaVARES \\ Universidade Nova de Lisboa \\ alice.tavares@gmail.com
}

Fecha de recepción: 25-10-2016

Fecha de aceptación: 23-2-2017

\section{RESUMO}

Este texto tem o objetivo de estudar as aves em Portugal, na Idade Média (séculos XIII$\mathrm{XV}$ ) e nos primórdios do século XVI, a partir de documentação jurídica, régia e local (costumes e foros, posturas, atas de vereação...) e dos livros de viagens, as Saudades da Terra, de Gaspar Frutuoso, sobre os arquipélagos portugueses, Açores e Madeira. Pretende-se, por um lado, dar a conhecer as aves que faziam parte da paisagem portuguesa; os conflitos e os delitos resultantes das relações quotidianas entre as pessoas e estes animais. Na segunda parte, analisaremos as penas, os mecanismos de controlo e as medidas "proteção" para a preservação das aves.

PALAVRAS-CHAVE: Portugal, aves, séculos XIII-XVI, conflitos, proteção.

\section{RESUMEN}

Este texto tiene el objetivo de estudiar las aves en Portugal, en la Edad Media (siglos XIII-XV) y a principios del siglo XVI, a partir de la documentación jurídica, regia y local (fueros extensos, ordenanzas, actas municipales...) y de los libros de viajes, las Saudades da Terra, de Gaspar Frutuoso, sobre los archipiélagos portugueses, Azores y Madeira. Se pretende, por un lado, dar a conocer las aves que formaban parte del paisaje portugués; los conflictos y los delitos resultantes 
de las relaciones cotidianas entre las personas y estos animales. En la segunda parte, analizaremos las penas, los mecanismos de control y las medidas de "protección" para la preservación de las aves.

PALABRAS CLAVE: Portugal, aves, siglos XIII-XVI, conflictos, protección.

\section{ABSTRACT}

This text describes the study of birds in the Middle Ages $\left(13^{\text {th }}-15^{\text {th }}\right.$ centuries $)$ and at the beginning of the $16^{\text {th }}$ Century in Portugal through both royal and local legal documents (customs and laws, municipal by-laws, minutes of the city councils, etc.) and Saudades da Terra, a series of travel books on the Azores and Madeira Islands by Gaspar Frutuoso. The study seeks to present the birds that were part of the Portuguese landscape as well as the conflicts and the crimes generated from daily relations between the people and these animals. In the second part, it will examine the punishment, control mechanisms and the "protection" measures for the bird's preservation.

KEY WORDS: Portugal, birds, $13^{\text {th- }} 16^{\text {th }}$ centuries, conflicts, protection.

\section{INTRODUÇÃO}

As aves exerceram um papel fundamental na vida quotidiana das populações rurais e urbanas, em Portugal, ao longo da Idade Média (séculos XIII-XV) e nos primórdios da modernidade (século XVI). Estas eram utilizadas para fins que iam além do objetivo final de usufruir da sua carne para a alimentação e ainda aportavam outros benefícios económicos importantes para o abastecimento e consumo das comunidades humanas ${ }^{1}$. Além disso, ressaltamos que a convivência com estes animais nem sempre foi pacífica, originando alguns problemas e danos para as gentes medievas e das primeiras décadas do século XVI. Por outro lado, as aves costumavam ser vítimas de delitos e de acidentes, pois chegavam a necessitar, muitas vezes, de proteção e de medidas preventivas, levantando assim o problema da sua preservação e de como esta seria feita. Encontramos, deste modo, vários documentos, entre os quais as disposições jurídicas, régias e locais e os livros de viagens portugueses, que espelham estas preocupações e, ao mesmo tempo, nos elucidam sobre os procedimentos e os mecanismos em prol deste tipo de fauna, tida como uma importante fonte de rendimento económico, como veremos mais adiante.

As temáticas sobre os animais, tais como as aves, não têm merecido muita atenção por parte da historiografia portuguesa, carecendo de estudos e de uma análise mais profunda e transdisciplinar. São portanto parcas as referências bibliográficas sobre estas problemáticas, indo um pouco mais além de alguns levantamentos e de coletâneas de documentação ${ }^{2}$

1 C. Pimenta, M. Moreno García e R. Varela Gomes, "Aves no prato e... não só! A ornitofauna recuperada no Setor Sul do Castelo de Silves", XELB: Revista de Arqueologia, Arte, Etnologia e História, 10 (2010), p. 401.

2 Vejam-se os seguintes exemplos: História Florestal, Aquícola e Cinegética. Coletânea de documentos existentes no Arquivo Nacional da Torre do Tombo -Chancelarias Reais-, vols. 1-6, Lisboa, Ministério da Agricultura e Pescas. Direção-Geral do Ordenamento e Gestão Florestal, 1980; C. M. Baeta Neves, "Aspetos históricos e atuais dos problemas da proteção da natureza em Portugal", Boletim da Sociedade Broteriana, 54 (1981), pp. 367-386; Íd., "Alguns documentos do Arquivo Nacional da Torre do Tombo sobre monteiros-mores, caçadores-mores e caçadores e couteiros das perdizes", Anais do Instituto Superior de Agronomia, 28 (1965), pp. 5-138; M. L. Ledesma Rubio, "La caza en las cartas de población y fueros de la Extremadura Aragonesa", Aragón en la Edad Media, 8 (1989), pp. 427 - 440. 
sobre as atividades cinegéticas, florestais e os agentes que as desenvolviam (caçadores e cetreiros, por exemplo) e os responsáveis régios e municipais (montanheiros, monteiros e outros veladores dos montes) encarregados de controlar e garantir o devido funcionamento destas práticas, segundo os preceitos definidos na documentação escrita. Já começaram, porém, a surgir alguns trabalhos sobre estes temas, mais recentemente, em 2015, com a obra, Animais e Companhia na História de Portugal ${ }^{3}$, colocando em cima da mesa novos contributos, assim como novas perspetivas de investigação, ao aglutinar vários campos do conhecimento, entre as quais a história e a história de arte. No entanto, estamos ainda diante de um longo caminho a percorrer e de uma série de questões pertinentes para conhecermos melhor as espécies, as suas origens, os seus habitats, as relações entre os homens e os animais e "a condição dos bichos", sobretudo numa perspetiva mais global, alargando os estudos para outras áreas científicas ${ }^{5}$. Também são poucos os trabalhos sobre a ecohistória e as relações antrópicas, onde à partida podemos encontrar informações relativas à fauna, à flora e às suas formas de exploração, inseridas num contexto mais alargado de análise em estudos sobre o meio natural, a evolução da paisagem e a organização do território, como acontece há alguns anos em Espanha, principalmente, numa perspetiva histórica ligada também ao direito e à história económica ${ }^{6}$.

Não obstante, chamamos também a atenção para o desenvolvimento de estudos arqueo-zoológicos sobre a ornitofauna portuguesa e espanhola que compunha a paisagem da Idade Média Peninsular, sobretudo numa perspetiva comparativa, com a finalidade de examinar e cotejar as fontes documentais com as análises osteológicas e arqueológicas das aves ${ }^{7}$. A ideia consiste em conjugar duas áreas do conhecimento diferentes entre si,

3 I. Drumond Braga e P. Drumond Braga (eds.), Animais e Companhia na História de Portugal, Lisboa, Círculo de Leitores, 2015. Nesta obra, estão presentes uma série de estudos sobre as relações entre os animais e os homens em diversas épocas até à atualidade, numa perspetiva transdisciplinar, sobretudo nas áreas das ciências sociais e humanas. Procurou-se estudar os animais sob diversos pontos de vistas, desde o utilitário, a arte, a literatura, entre outros.

4 I. Drumond Braga e P. Drumond Braga, "Fazer a História dos Animais", em Animais e Companhia..., p. 23.

5 Para o caso português, podemos contar com os estudos de I. Gonçalves, Por terras de Entre-Douro-EMinho com as Inquirições de D. Afonso III, Porto, Edições Afrontamento e CITCEM-Centro de Investigação Transdisciplinar "Cultura, Espaço e Memória", 2012; Íd., "Espaços silvestres para animais, no noroeste de Portugal, com as inquirições de 1258", em Estudos em Homenagem ao Professor Doutor José Marques, vol. 2, Porto, Faculdade de Letras da Universidade do Porto, 2006, pp. 193-219; C. Crespo, Falcoaria. Arte Real, Lisboa, CTT, 2013; Íd., A arte da falcoaria, Lisboa, Edições Inapa, 1999; G. Coralejo Moiteiro, "Paisagens históricas: a flora e a fauna na toponímia meridional beirã de quinhentos", em Paisagens Rurais e UrbanasFontes, Metodologias, Problemáticas. Atas das Primeiras Jornadas, Lisboa, Centro de Estudos Históricos da Faculdade de Ciências Sociais e Humanas da Universidade Nova de Lisboa, 2005, pp. 25-63.

6 Dispomos, a modo de exemplo, dos estudos de Julián Clemente Ramos, José Matellanes Merchán, entre outros estudiosos. Destacamos também para os trabalhos reunidos nas atas do I Congresso sobre Ecohistoria e História Medieval realizado em Espanha, J. Clemente Ramos (ed.), El medio natural en la España medieval. Actas del I Congreso sobre Ecohistoria e Historia Medieval, Cáceres, Universidade de Extremadura, 2001. Sobre a caça e o desenvolvimento de outras atividades económica veja-se o exemplo do trabalho de M. L. Rodrigo Estevan, "Cazar y comer caza en el Aragón medieval: fueros, normativas, prácticas y creencias", El Ruejo: Revista de Estudios Históricos y Sociales, 5 (2004), pp. 59-124; M. L. Ledesma Rubio, "La caza en...", pp. 427-440; M. Á. Ladero Quesada, "La caza en la legislación municipal castellana. Siglos XIII a XVIII", En la España Medieval, 1 (1980), pp. 193-221, http://www.ucm.es/BUCM/revistas/ghi/02143038/articulos/ ELEM8080110193A.PDF> (Consulta: 15-7-2010); P. Drumond Braga, "Divertimento, utilitarismo e barbárie: a caça", em Animais e Companhia..., pp. 185-215.

7 Vejamos os seguintes estudos elaborados quer por investigadores e docentes portugueses, quer por espanhóis: D. C. Morales Muñiz, "Las aves cinegéticas en la Castilla Medieval según las fuentes documentales y zooarqueológicas. Un estudio comparativo", em Actas del Congreso Internacional La Caza en la Edad Media, Tordesillas, Seminario de Filología Medieval, 2002, pp. 129-150; C. Pimenta, M. Moreno García e 
com o objetivo de conseguir um estudo mais profundo sobre as espécies faunísticas e as suas caraterísticas; as atividades económicas e sociais que envolviam as aves e os hábitos de consumo das comunidades de determinada época.

Neste sentido, estamos diante de uma oportunidade para estudarmos as aves em Portugal (continental e insular) ao longo de um período de amplo espectro (séculos XIIIprincípios do século $X \mathrm{VI}$ ), revisitando as fontes jurídicas e literárias sobre viagens, sob um outro prisma. Temos assim a intenção de lançar pistas e interrogações para investigações futuras, ao fazer um trabalho de análise, de levantamento e de pesquisa na busca de referências sobre a fauna ornitológica.

Este texto tem, portanto, um duplo enfoque: dar a conhecer, por um lado, as aves que faziam parte da paisagem do reino português, limitando-nos ao continente e aos arquipélagos da Madeira e dos Açores, e, por outro lado, analisar os conflitos, os mecanismos de controlo e de proteção que advinham da relação entre estes animais e as populações mediévicas e dos primórdios do século XVI. Neste trabalho de análise, referir-nos-emos também à fauna ornitológica dos arquipélagos da Madeira (1419) e dos Açores (1439), como já referimos, atendendo que estas ilhas foram descobertas e povoadas ainda no século XV. Há ainda outras razões para incluirmos as ilhas neste estudo, uma vez que, em primeiro lugar, podemos encontrar mais indicações sobre outro tipo de espécies, autóctones e exógenas, e os seus usos nas fontes jurídicas e literárias de viagens açorianas e madeirenses, que não nos foi possível encontrar na documentação relativa ao continente. Em segundo lugar, há que frisar que as ilhas dos Açores e da Madeira eram territórios virgens, quando foram descobertas, dispondo de caraterísticas naturais e ambientais peculiares que foram sofrendo alterações, fruto da ação humana. Deste modo, conseguiremos complementar a nossa análise, contribuindo assim para o seu enriquecimento.

Os dados que servirão de base a este estudo foram recolhidos em documentação da Idade Média Portuguesa, maioritariamente, entre o século XIII e os princípios do $\mathrm{XVI}$, como acabamos de referir. Entre ela, destacam-se as fontes de natureza jurídica, municipal-costumes e foros, posturas, atas de vereação...-e régia-ordenações, diplomas de chancelaria, por exemplo-, bem como os livros de viagens, sobretudo, os de Gaspar Frutuoso, com descrições sobre os arquipélagos atlânticos que compõem a Macaronésia ${ }^{8}$.

As fontes jurídicas, principalmente os regulamentos locais -costumes e foros, as posturas e as atas de vereação-, são fundamentais para o desenvolvimento deste tipo de análise, porque regulamentam toda a vida municipal, permitindo-nos uma maior aproximação da realidade quotidiana das populações. Este tipo de documentação dá-nos ainda a possibilidade de observar as relações entre as comunidades humanas, o meio natural e os mecanismos de exploração dos recursos. É através deles e das decisões municipais que temos ainda a possibilidade de entender os problemas, com os quais as gentes medievas e dos alvores da modernidade se confrontaram e as suas respetivas soluções. Encontramos também uma clara coincidência de objetivos e de conteúdos entre as fontes jurídicas, locais e régias, ao definirem normas e novas condutas, no sentido de preservar e defender as aves; de punir e controlar os danos causados por elas e as agressões de que eram vítimas,

R. Varela Gomes, "Aves no prato..., pp. 399-420; M. Moreno García, C. Pimenta, "Beyond chicken. Avian biodiversity in a Portuguese late medieval urban site", Groningen Archaeological Studies, 10 (2010), pp. 235265; M. Moreno e S. Davis. Estudio de las Asociaciones Faunísticas recuperadas en Alcácer Do Sal, convento de Sao Francisco, Santarém y sé de Lisboa, Lisboa, Ministerio da Cultura. IPPAR. Junta de Extremadura e Correiros, 2001, pp. 231-255.

8 Termo utilizado para designar os arquipélagos localizados no Atlântico Norte (Açores, Madeira, Canárias e Cabo Verde) e a faixa costeira do noroeste de África, entre Marrocos e Senegal. 
ao serem contempladas numa série de normativas e de leis de origens jurídicas diferentes (régia e concelhia), com os seus respetivos enquadramentos penais e medidas preventivas de controlo, como, por exemplo, a vigilância e a salvaguarda dos espaços naturais, inclusive da fauna ornitológica.

Ainda que sejam fontes de natureza diferente das anteriores, os livros de viagens ${ }^{9}$, como a obra de Gaspar Frutuoso, Saudades da Terra, redigidas entre 1586 e 1590, serão usados neste estudo, no sentido de estarmos diante de relatos bastante detalhados sobre os arquipélagos atlânticos, actualmente os territórios portugueses insulares -Açores e Madeira-, que expressam novas formas de conhecimento e nos aportam inúmeras informações e descrições sobre a paisagem; a gestão do espaço e do meio natural, bem como os conflitos e as vivências quotidianas das comunidades acabadas de assentar em novos territórios com caraterísticas diferentes ao continente, um pouco à semelhança dos diplomas e dos regulamentos concelhios. Mas, com um cariz diferente, pois nesta obra não encontramos geralmente menções aos enquadramentos penais nos relatos de viagens. Nestas fontes podemos também dispor de informações sobre a diversa fauna ornitológica das ilhas açorianas e madeirenses, a propósito dos descobrimentos e da expansão portuguesa, entre as quais, os seus usos e os modos como as populações se relacionavam com estes animais, proporcionando-nos um melhor entendimento sobre as diferentes realidades insulares portuguesas. Por outro lado, há que acrescentar que as fontes jurídicas e literárias têm traços em comum: os animais; neste caso, em concreto, as aves que serão o ponto neurálgico desta análise.

Este estudo divide-se portanto em duas partes. Em primeiro lugar, analisaremos os mais variados conflitos, indo mais além das questões relacionadas com a exploração, a atividade cinegética e com o controlo dos recursos ambientais e económicos dos concelhos. É também de salientar que as aves eram ainda motivo de outros problemas económicos, fiscais e jurídicos, suscitando a animosidade das pessoas, sobretudo, nas relações comerciais, na cobrança fiscal e na proteção dos seus bens, que não iremos aprofundar aqui, circunscrevendo-nos apenas às questões dos conflitos e da proteção. Por seu turno, estes animais costumavam ser vítimas de delitos e de acidentes levados a cabo pelas pessoas, causando-Ihes danos e destruindo os seus habitats.

Num segundo momento refletiremos sobre as molduras penais que os delitos e os conflitos acarretavam, assim como as medidas de proteção necessárias para a preservação das aves e dos seus espaços envolventes, pois eram entendidas como uma fonte de riqueza económica e ambiental no quotidiano medieval e dos inícios do século XVI. Antes de avançarmos, é importante frisar, que quando falamos de "proteção" e de questões ecológicas de conservação do meio natural, como a fauna, -neste caso as aves-, não as podemos entender segundo os parâmetros atuais de preservação ambiental, desenvolvidos a partir do final do século XVIII ${ }^{10}$, para não cairmos numa situação de anacronismo no uso de determinados conceitos, que foram formulados séculos depois, ao tecermos considerações sobre o período escolhido para estudarmos. Apesar de estarmos diante de noções e ideias contemporâneas, as fontes selecionadas deixam já transparecer uma clara consciência das gentes medievas e dos inícios do século XVI em preservar os seus recursos naturais e económicos, procurando fazer uma gestão adequada em função das suas necessidades,

9 Vejam-se os seguintes relatos de viagens: G. Frutuoso, As saudades da terra, vols. 1-6, Ponta Delgada, Instituto Cultural de Ponta Delgada, 1998; J. Münzer, Viaje por España y Portugal (1494-1495), Madrid, Talleres Aldua, 1951.

10 J. P. Delénge, História da ecologia. Uma ciência do homem e da natureza, Lisboa, Dom Quixote, 1993; J. M. Drouin, Reinventar a natureza. A ecologia e a sua história, Lisboa, Instituto Piaget, 1993. 
prevenindo e combatendo as transgressões e os delitos decorrentes da exploração do meio natural. Passemos de seguida à análise dos delitos e dos conflitos entre as populações e os animais.

\section{AVES, CONFLITOS E OUTROS PROBLEMAS NA VIDA QUOTIDIANA}

Tendo como suporte as fontes mencionadas, constatamos facilmente que a paisagem de Portugal continental e dos arquipélagos era composta por diversas espécies ornitológicas, fazendo parte do quotidiano das comunidades mediévicas e dos alvores da modernidade. Encontramos assim as pombas, os gansos, as perdizes, as rolas, os abutres, os açores, os gaviões, as galinhas e entre outras aves. Já nos arquipélagos dos Açores e da Madeira encontramos ainda referências a outras espécies ornitológicas caraterísticas das paisagens insulares, tais como as pardelas, os estapagados, os canários e os garajaus, como podemos verificar através das descrições das paisagens no livro de viagens de Gaspar Frutuoso.

Ao fazermos uma simples leitura das fontes detetamos facilmente que as aves eram, por um lado, vistas como animais essenciais e utilitários, uma vez que colmatavam as necessidades alimentares, de abastecimento, de consumo e económicas das populações, permitindo o desenvolvimento da caça, da "indústria" e do comércio. Temos, assim, o exemplo dos estapagados e das pardelas açorianas, que costumavam ser capturadas para a produção de óleo, visto que as suas peles e as penas eram ricas em gordura11. Por outro lado, algumas aves, tais como as de cetraria, eram utilizadas como instrumentos de trabalho, servindo de suporte nas atividades cinegéticas, em conjunto com outros animais, cães e furões.

Não obstante, podemos concluir que nem sempre as relações entre as pessoas e as aves costumavam ser pacíficas, uma vez que estes animais estavam na origem de alguns problemas e desacatos. Sendo assim, esta problemática permite-nos levantar algumas questões sobre os conflitos com que as populações rurais e urbanas se deparavam com estes animais, as suas respetivas soluções e as penalizações estipuladas, como verificamos a partir das fontes, sobretudo de natureza jurídica, entre as quais destacamos a legislação municipal e alguns diplomas régios medievais (séculos XIII-XV) e dos primórdios do século $\mathrm{XVI}$, com a finalidade de regular os coutos e de responder às queixas dos povos. Partindo destes pressupostos, sabemos que, umas vezes, as aves eram a causa de delitos e de transgressões, outras eram alvo de crimes e incidentes provocados pela ação humana. Muitos dos conflitos estavam relacionados com a utilização destes animais na alimentação, assim como no desenvolvimento das atividades agrícolas, pecuárias e cinegéticas.

Procedamos, desta forma, à análise dos delitos e das situações de animosidade relacionados com as aves. Em primeiro lugar, começamos por salientar os danos causados, principalmente, nas propriedades agrícolas, à procura de alimentos, tais como frutos, cereais e sementes, esgaravatando e revolvendo os solos. Deste modo, prejudicavam a produção agrícola e os campos. Sendo assim, em Loulé, segundo as atas das vereações, datadas de 21 de abril de 1378, dispomos de uma medida camarária que consistia na isenção de penas para aqueles que matassem as aves, incentivando-os a ficar com elas, com o fim de evitar mais estragos nas searas ${ }^{12}$. Por outro lado, esta iniciativa pode ter, porém, outra interpretação associada ao controlo e à redução das populações de determinadas espécies ornitológicas, com o fim de minimizar a destruição das culturas.

11 G. Frutuoso, Saudades da Terra..., pp. 232-233.

12 H. Baquero Moreno (ed.), Atas das vereações de Loulé, vol. 1, Porto, Câmara Municipal de Loulé, 1984, p. 28; M. Á. Ladero Quesada, "La caza en...", p. 203. 
Ao cotejarmos os livros de viagens, podemos também detetar que na ilha de Santa Maria (Açores), os bilhafres, os canários, os estapagados, os estorninhos, as garças, os sachões e as mélroas ${ }^{13}$ eram responsáveis pelos danos provocados nas terras cerealíferas, tornando-se num problema para as suas gentes. A situação era análoga quando se tratava de estragos causados pelos pombos torcazes nas ilhas do complexo oriental do arquipélago dos Açores, São Miguel e Santa Maria ${ }^{14}$. De igual forma, na ilha de Porto Santo (arquipélago da Madeira), as vinhas e as árvores de fruto, tais como as amoreiras e as figueiras, não escaparam igualmente à ação das mélroas que tinham o hábito de comer os seus frutos, lesando, mais uma vez, os seus proprietários ${ }^{15}$.

A atividade cinegética constituiu um problema quer para as autoridades régias, quer para os concelhos, embora se tratasse de uma prática especialmente regulamentada, chegando ao ponto de falarmos de uma espécie de «direito de caça». Ou seja, a legislação local e as disposições gerais do reino refletem uma notória preocupação em definir o funcionamento desta atividade, desde as técnicas usadas (armadilhas, armas, animais, etc); a distribuição e a fixação dos direitos de propriedade das peças de caça e, por fim, a organização que as áreas coutadas deveriam seguir, sobre as quais nos iremos debruçar.

É, através destas premissas, que conseguimos identificar um dos conflitos entre as populações e as aves, que reside nas formas de rentabilização dos recursos das coutadas, entre os quais os florestais, os ornitológicos -perdizes, codornizes, galinhas, pombas, rolas, por exemplo- e também de outros animais, tais como coelhos e lebres. Antes de mais, convêm frisar que este facto está ainda associado às caraterísticas deste tipo de propriedades que consiste em terrenos que estavam devidamente demarcados para limitar, proibir a captura de determinadas espécies e impedir certas práticas de exploração de recursos naturais, restringindo-os à maioria das populações, a favor de uma minoria interessada nas suas atividades cinegéticas, mais por ócio e entretenimento do que na obtenção de bens alimentares ${ }^{16}$.

Diante deste cenário, podemos constatar uma clara colisão de interesses e de modos de vida partilhados por grupos sociais diferentes, que se irá verificar na gestão e na exploração destes espaços rurais. Ou seja, temos, por um lado, uma elite que pretendia usufruir destes bens naturais, dando azo às suas atividades lúdicas e de destreza na caça, sobretudo de animais de grande de porte, pois esta prática estava também conotada com o desenvolvimento de aptidões bélicas. Por outro lado, temos a maioria da população que se servia destes recursos para satisfazer as suas necessidades alimentares e económicas, indispensáveis à sobrevivência.

Para agravar esta situação de conflito, é-nos possível detetar claramente nas fontes, que nem sempre as regras das áreas coutadas eram tidas em consideração, uma vez que são constantemente repetidas nos códigos locais e nos diplomas régios ao longo de três séculos. Segundo estes, devia-se proceder à proibição da exploração inadequada dos recursos florestais, tais como cortar madeira, lenha e tirar palha. Além disso, visavam controlar a caça e outras práticas, dando-nos conta das potencialidades faunísticas e da capacidade de "conservar", de certo modo, numa perspetiva atual, os animais e outros bens naturais. Sendo assim, podemos afirmar que os interesses régios e os de uma minoria de senhores nobres e eclesiásticos nas áreas coutadas, propiciaram, por um lado, a "preservação de algumas 
espécies, que de outro modo teriam sido dizimadas pelas populações"17. Por outro lado, ao colocarmos o problema sob outra ótica convêm também sublinhar que esta consciência de "preservar" está associada à clara preocupação em salvaguardar determinados recursos florestais e económicos essenciais para o desenvolvimento das atividades económicas (a caça, por exemplo), o abastecimento e consumo diários das populações.

As normativas locais e as disposições régias oferecem-nos ainda outras informações, permitindo-nos conhecer e indagar as medidas de salvaguarda dos coutos e as condições de gestão destes espaços privados. Atendamos ao seguinte exemplo. Neles podiamse caçar determinadas espécies, entre as quais, as codornizes, as perdizes, as aves de cetraria, entre outras aves, em certas alturas do ano, exceto nos períodos de veda. Dito de outra forma, durante este período, entre o fim do inverno e o início do verão, estava proibida a caça de algumas espécies, de modo a respeitar os ciclos biológicos de reprodução e os períodos de crescimento das aves. Este procedimento não era, contudo, tido em linha de conta como as fontes nos deixam transparecer. Se fosse cumprido, não teríamos tido acesso às várias indicações que podemos encontrar na documentação compulsada, como, por exemplo o diploma, emitido em 20 de abril de 1480, a propósito da caça do açor, na Serra da Estrela. Este documento atesta a proibição da captura desta ave, exceto, após o dia de São João, isto é, a partir do fim do mês de Junho ${ }^{18}$. Estamos, portanto, diante da fixação de um período de veda de caça, partindo do princípio que o açor é uma ave que se pode encontrar mais facilmente no início da Primavera, aquando das suas demonstrações de acasalamento. Além disso, há que ter em linha de conta que a fêmea açor põe os ovos entre o fim de Março e o fim do mês de Abril e as crias permanecem trinta e cinco a quarenta dias no ninho ${ }^{19}$. Com este tipo de preocupações, podemos também inferir uma clara necessidade de restringir a caça furtiva e sem controlo, sobretudo de espécies de caça menor.

Uma das caraterísticas associada aos coutos consistiu na definição de regras sobre o uso de determinadas técnicas cinegéticas, mencionadas nos diplomas régios, fazendo alusão, principalmente à utilização de "más artes", com o objetivo de minimizar os conflitos que daí advinham. Colocado de outra forma, dispomos assim de indicações relativas à utilização de recursos daninhos e prejudiciais para os animais durante a caça, constituindo um problema não só para as aves (perdizes, codornizes e rolas, por exemplo), mas também para os leporídeos. Neste sentido, registamos que, nas áreas coutadas, a caça das aves não podia ser feita com as seguintes armadilhas: redes, cordas, pedras, construção de "cevadouros" e entre outros ardis ${ }^{20}$. Tratavam-se, pois, de recursos simples e pouco dispendiosos, acessíveis à maioria dos indivíduos. Além disso, podemos intuir que esta proibição está relacionada com uma possível caça desenfreada, ao "ser capaces de capturar en poco tiempo una amplia gama de especies, sin reparar em que sean comestibles o no, o se trate de crías o ejemplares adultos"21. Já o uso de candeias, apesar das punições que acarretava, indicava que a prática da caça noturna de perdizes seria frequente, com

17 Ibídem, p. 186.

18 História Florestal, Aquícola e...", vol. 2, pp. 208-209.

19 J. Nicolai, Aves de Rapina. Diurnas e noturnas, [s/c], Everest Editora, [s.a], p. 65.

20 A. Morales Muñiz y D. Carmen Morales Muñiz, “¿De quién es este ciervo? Algunas consideraciones en torno a la fauna cinegética de la España medieval”, em El medio natural en la España medieval..., p. 394; D. C. Morales Muñiz, "Las aves cinegéticas...", p. 142.

21 História Florestal, Aquícola e..., vol. 2, pp. 205-207; M. L. Rodrigo Estevan, "Cazar y comer caza...", p. 97; D. C. Morales Muñiz, "Las aves cinegéticas...", p. 143; C. Pimenta, M. Moreno García e R. Varela Gomes "Aves no prato...", p. 407. 
o objetivo de assustar as aves, atraindo-as às redes ou para outras armadilhas ${ }^{22}$. A partir dos livros de viagens, temos também conhecimento que as fogueiras eram utilizadas nos Açores para caçar pardelas, estapagados e outras aves, nos meses de maio e junho ${ }^{23}$. A partir do exemplo acabado de enunciar, podemos interpretar que a proibição do uso do fogo estava relacionada com o risco de incêndio que as matas e os montes poderiam sofrer, transformando-se também numa ameaça para as populações ${ }^{24}$.

Outros estratagemas mais complicados e engenhosos foram igualmente utilizados e proibidos, como, por exemplo, o uso de outras aves, os perdigões de "chamado" (em cativeiro $)^{25}$, e a caça com bois para chamar a atenção destes animais. Este último ardil era utilizado para enganar as aves, especialmente as perdizes, uma vez que estas tinham o hábito de andar à volta de animais quadrúpedes, tais como os bois e os equinos, entre outros. Esta técnica implicava um disfarce de boi, utilizado pelo caçador para atrair as referidas aves, com o fim de simular o seu aspeto e os seus comportamentos, enganandoas. O falso animal chamaria assim a atenção das perdizes para as encurralar e as levar a outras armadilhas, podendo ser capturadas com redes ou com outros artifícios ${ }^{26}$.

Analisando a documentação selecionada, constatamos que os cães, os furões e as aves de cetraria eram animais bastante usados na caça, devido às suas capacidades predatórias. Estes eram auxiliares fundamentais para os caçadores, ajudando-os na perseguição e na captura das presas, mas também eram uma fonte de conflitos. Estes animais foram objeto de regulamentação, embora não tenhamos um conhecimento profundo sobre as normas e as leis relativas a determinadas raças de cães, tais como os alãos, os podengos e os galgos, tipicamente usadas na caça. Por exemplo, um dos problemas que conseguimos observar, através das proibições na documentação compulsada, mais em concreto, nos diplomas régios, relaciona-se com a utilização de animais predatórios na caça de perdizes e de outras aves, nas coutadas. Pretendia-se, deste modo, apostar na preservação e manutenção nos referidos coutos, bem como das espécies. Estes regulamentos régios estão ainda associados a outras interpretações relacionadas com o uso dos cães, porque os referidos animais causavam normalmente destroços nas propriedades agrícolas e nos bens comunais, sobretudo durante a Primavera, momento que corresponde ao nascimento e florescimento dos frutos, das colheitas e à reprodução das aves ${ }^{27}$.

A partir dos diplomas régios objeto de estudo temos também conhecimento de mais uma modalidade -a caça com besta- que não estava alcance da maioria dos camponeses e dos caçadores, exigindo, portanto, recursos financeiros e destreza para a utilizar que só um grupo reduzido de indivíduos possuía ${ }^{28}$. Esta prática cinegética era normalmente utilizada na captura de aves, coelhos e lebres, estando igualmente proibida e, além disso, era alvo de sanções pecuniárias, como devia acontecer em Évora, a propósito da caça de pombas mansas.

22 História Florestal, Aquícola e..., pp. 205-207; M. L. Rodrigo Estevan, “Cazar y comer caza...", p. 98.

23 G. Frutuoso, Saudades da Terra..., p. 233.

24 J. G. Martínez Martínez, El delito ecológico en los Fueros de Coria y Cáceres (un estudio inshistórico textual-comparativo, Cáceres, JGMM. Zigurat Libros, 2001, pp. 70-71.

25 História Florestal, Aquícola e..., pp. 205-207; M. L. Rodrigo Estevan, “Cazar y comer caza...”, p. 98; D. C. Morales Muñiz, "Las aves cinegéticas...", p. 143.

26 História Florestal, Aquícola e..., pp. 205-207; M. L. Rodrigo Estevan, “Cazar y comer caza...”, p. 100.

27 Posturas Municipais portuguesas. (séculos XIV-XVIII), Ponta Delgada, Centro de Estudos Gaspar Frutuoso. Centro Interdisciplinar de História, Culturas e Sociedades, 2012, p. 45.

28 História Florestal, Aquícola e..., pp. 205-207; M. L. Rodrigo Estevan, “Cazar y comer caza...", p. 97. 
Ainda dentro desta linha de pensamento, enunciamos outro problema com que as populações se deparavam relacionado com o desenvolvimento da caça, coligindo com os interesses e as necessidades económicas dos agricultores e dos ganadeiros. Tendo em conta a documentação selecionada, estes últimos tinham o hábito de ver as suas terras, as suas culturas e os seus pastos danificados por causa dos caçadores e da passagem de animais pelas suas propriedades, devastando-as. Centremo-nos, assim, no caso da coutada da lezíria de Sacarabotão, em Santarém, com base num documento redigido a 25 de junho de 1472. Este diploma faz alusão à destruição das terras, principalmente as cerealíferas, com a passagem dos caçadores ao caçarem rolas, codornizes e outras aves ${ }^{29}$. O mesmo se pode dizer das vinhas de Évora, devido às deslocações dos caçadores e à colocação de armadilhas para as perdizes e as lebres, como nos elucidam as suas posturas camarárias $^{30}$.

Os problemas com a caça apresentam outros matizes, quando se trata de rivalidades e de situações de tensão provocadas por indivíduos de fora que entravam nos concelhos para usufruírem dos montes e dos bosques alheios, contribuindo, desta forma, para a destruição e diminuição dos recursos cinegéticos e florestais municipais. Diante de este cenário, as autoridades camarárias dispunham de medidas destinadas especialmente aos forasteiros para explorar e tirar partido da fauna ou dos bens silvícolas, mediante autorização concelhia, segundo os costumes e foros de Riba-Côa (século XIII) ${ }^{31}$. Deste modo, os concelhos tentaram controlar a caça furtiva e a exploração desenfreada dos recursos naturais destinados às suas próprias gentes. No entanto, podemos ainda acrescentar que o estabelecimento dos coutos colidia com as necessidades das populações, sobretudo as mais desfavorecidas, que costumavam tirar proveito das potencialidades dos bosques. É, o caso dos habitantes da Serra de Ossa (no Alentejo) que receberam uma carta régia de privilégio, em 1491, no seguimento das suas queixas, dando-Ihes licença para caçar perdizes, veados, lebres, coelhos e porcos monteses ${ }^{32}$, cujos animais estavam à partida reservados para uma minoria privilegiada ${ }^{33}$.

Contudo, notamos através das fontes selecionadas, a existência de conflitos ocasionados pelas aves nos centros urbanos, visto que estas eram também causadoras de danos e de problemas de higiene e de salubridade. Apesar de encontrarmos referências pontuais sobre este tipo de situações constatamos que, em Lisboa, as galinhas eram animais nocivos, pois costumavam estar na origem de estragos e, além disso provocavam sujidades e imundices, segundo a postura camarária, de 18 de dezembro de 1496. Deste modo, definiu-se também a proibição de levar e de criar galinhas na barroca de São Francisco ${ }^{34}$.

29 História Florestal, Aquícola e..., pp. 185-186.

30 Posturas municipais portuguesas..., p. 153.

31 "Costumes e foros de Castelo Bom", Portvgaliae Monumenta Histórica. Leges et Consuetodines, vol. I, Olisipone, IUSSU Academiae Seicentiarum Olisiponensis, MDCCCLVI, p. 790, Título [409]. No caso das aves de rapina, confrontemos as normativas costumeiras dos concelhos espanhóis de Cáceres e Usagre, localizados na Extremadura espanhola e pertencem também da família de Costumes e Foros de Riba-Côa, que visavam a punição de indivíduos estranhos, de fora dos concelhos, que caçassem gaviões, açores e falcões. "Fuero de Cáceres", P. Lumbreras Valiente, Los Fueros Municipales de Cáceres. Su derecho público (Tesis Doctoral), Cáceres, Excmo. Ayuntamiento de la Capital de la Alta Extremadura, 1974, p. 11, Título 5; "Fuero de Usagre", R. de Ureña y Smenjaud e A. Bonilla y San Martin (eds.), Fuero de Usagre (siglo XIII), Madrid, Hijos de Reus, 1907, pp. 3-4, Título 6.

32 História Florestal, Aquícola e..., vol. 3, pp. 141-142.

33 P. Drumond Braga, "Divertimento, utilitarismo e...", pp. 185-186.

34 M. T. Campos Rodrigues (ed.), Livro das Posturas Antigas, Lisboa, Câmara Municipal de Lisboa, 1974, p. 4; I. Drumond Braga, "Perigos e ameaças animais", em Animais e Companhia..., p. 159; I. Gonçalves, 
Esta postura reflete portanto os esforços contínuos que os concelhos demonstravam em tentar manter a cidade limpa e a preocupação pela sanidade e pela higiene das pessoas.

Chegando a este ponto da nossa análise, apresentamos outra faceta dos conflitos que envolviam as aves: os crimes que eram perpetrados contra elas devido à ação humana. Começamos, assim, por enunciar os maus tratos de que costumavam ser vítimas, acabando por prejudicar indiretamente aos seus donos, visto que ficavam com os seus animais magoados ou mortos. Estes factos não deixavam de trazer implicações no desenrolar das suas atividades económicas, tais como a caça. As aves de cetraria constituem um exemplo, pois eram usadas como instrumentos de trabalho e de apoio dos caçadores, proporcionando voos altos ou baixos, consoante o tipo de presa. São aves que recebem um treino específico para perseguir e capturar determinados animais no ar ou em terra, tais como perdizes, codornizes, coelhos e entre outros. Ou seja, os "halcones bornís eran empleados para la caza de liebres y perdices, y los gavilanes o esparveles daban buenos resultados para apresar tordos, mochuelos, perdigones, palomas y grajos" ${ }^{\prime 3}$. Neste sentido, nas vilas de Riba-Côa -Alfaiates (1209-1229), Castelo melhor (1237), Castelo Bom (1237) e Castelo Rodrigo (1211-1237)-, encontramos, portanto, uma série de normativas costumeiras que visavam penalizar todos aqueles que fizessem danos em açores, falcões e gaviões, embora não tenhamos referências das sanções implicadas, mostrando assim um sentido especial pela preservação e bem-estar destas aves de presa ${ }^{36}$, tão importantes na caça.

A captura das pombas de pombal (domésticas) constituiu um outro problema nos concelhos ribacoanos e da Guarda ${ }^{37}$. Tratavam-se, assim, de animais protegidos, como podemos deduzir a partir dos seus costumes e foros. Deste modo, depreendemos que a proteção destas aves estava não só relacionada com a preservação dos seus espaços de criação, mas também com uma razão de fundo económico, vinculada com a prática de atividades agrárias, porque o "excremento, la palomina, fue uno de los mas importantes fertilizantes utilizados en la Edad Media"38. O mesmo se pode dizer das galinhas, dos gansos e das outras aves domésticas que estavam igualmente protegidas, pois as normativas locais são claras ao determinar as penas pecuniárias para a caça e a morte destes animais ${ }^{39}$.

Já as aves em estado selvagem, tais como os abutres, constituem mais um exemplo dos animais que costumavam padecer de "maus tratos". Sabemos que, nas vilas de São Martinho de Outeiro e de Viana de Lima, havia o hábito de espantar, assustar, capturar e matar os abutres, como depreendemos a partir de um diploma régio de meados do século "Posturas municipais e vida urbana na Baixa Idade Média: o exemplo de Lisboa", em Um olhar sobre a cidade
medieval, Cascais, Patrimonia Histórica, 1996, p. 86.

35 M. L. Rodrigo Estevan, "Cazar y comer caza...", p. 94.

36 "Costumes e foros de Alfaiates", Portvgaliae Monumenta Histórica..., p. 807, Título [147]; "Costumes e foros de Castelo Bom", Portvgaliae Monumenta Histórica..., p. 762, Título [153]; "Costumes e foros de Castelo Melhor", Portvgaliae Monumenta Histórica..., p. 931, Título [309], Livro 8; "Costumes e Castelo Rodrigo", Portvgaliae Monumenta Histórica..., p. 931, Título [323], Livro 8.

37 "Costumes e foros de Alfaiates", Portvgaliae Monumenta Histórica..., p. 807, Títulos [147], [148] e p. 837, Título [431]; "Costumes e foros de Castelo Bom", Portvgaliae Monumenta Histórica..., p. 762, Título [153]; "Costumes e foros de Castelo Melhor", Portvgaliae Monumenta Histórica..., p. 931, Título [309], Livro 8; "Costumes e foros de Castelo Rodrigo", Portvgaliae Monumenta Histórica..., p. 948, Título [323], Livro 8; "Costumes e foros da Guarda", Portvgaliae Monumenta Histórica..., p. 9, Título [90] e p. 11, Título [137]; M. L. Rodrigo Estevan, "Cazar y comer caza...", p. 94.

38 J. V. Matellanes Merchán, "Aproximación a la política ecológica y cinegética en los fueros del siglo XIII", em El medio natural en la España medieval..., pp. 347-348; M. Á. Ladero Quesada, “La caza en...”, p. 203.

39 "Costumes e foros da Guarda", Portvgaliae Monumenta Histórica..., p. 11, Título [147]. 
XV (30 de abril de 1491), emitido com o propósito de sancionar os comportamentos violentos que estas aves necrófagas recebiam ${ }^{40}$.

Por fim, analisemos os problemas que o furto das aves ${ }^{41}$, dos ovos e das crias ocasionava, pois estamos diante de uma forma, ainda que indireta, de provocar danos nestes animais e nos seus donos que ficavam privados dos seus bens. Sendo assim, podemos verificar que, nestes casos, a legislação mediévica é também bastante clara ao evidenciar a preocupação das autoridades judiciais régias e locais em defender os ninhos e os ovos, com o objetivo de salvaguardar os ciclos de reprodução, possibilitar o nascimento e o crescimento das aves. Por outras palavras, as fontes em estudo frisam a importância e a necessidade de conservar os habitats e de não "interferir en el ciclo biológico de determinados animales" 42 . Este facto reflete, mais uma vez, a consciência nítida das populações em respeitar e preservar os recursos naturais, neste caso, os faunísticos, permitindo o desenvolvimento e o crescimento dos animais nas melhores condições e nos seus meios naturais.

\section{AVES E PROTEÇÃO: PENALIZAÇÕES E MEDIDAS PREVENTIVAS}

Apresentados os conflitos e os problemas relacionados com as aves, passemos então à análise das molduras penais e das medidas preventivas apresentadas nos diversos instrumentos jurídicos, a ter em conta pelas populações, com o fim de minimizar os problemas e as situações de tensão resultantes das relações entre as aves e as pessoas e de combater as transgressões contra a fauna ornitológica, apostando no cuidado e na preservação destes animais. Cabe-nos, portanto, fazer uma reflexão sobre os conteúdos das mesmas e como as autoridades régias ou municipais puseram em marcha algumas medidas preventivas.

A proibição de determinados comportamentos e condutas foi, em primeiro lugar, a opção mais comum, usada pelas autoridades judiciais, associada a uma série de disposições coercivas, como podemos ver de forma bem patente na documentação que nos serve de suporte ao longo deste estudo, compreendo um período de largo espectro, entre os séculos XIII e as primeiras décadas do XVI.

Encontramos, neste sentido, uma série de penalizações que acompanhavam geralmente as proibições, variando em função do tipo de delitos. Por outras palavras, na análise das penas a aplicar eram tidos em consideração diversos fatores: a natureza, a gravidade, a tipologia do crime, o local, a hora do dia (dia ou noite), as motivações, a condição social do agressor e da vítima e entre outros parâmetros ${ }^{43}$. Ao analisarmos a documentação jurídica objeto de estudo, as sanções pecuniárias constituem assim a penalização mais generalizada ${ }^{44}$, cujos valores oscilavam consoante o crime, o estatuto social e religioso dos indivíduos e entre outros fatores. Estas eram normalmente divididas em duas partes: entre a vítima e o concelho ou algum outro funcionário local ou do rei,

40 História Florestal, Aquícola e..., pp. 88-89.

41 Ordenações Afonsinas, vol. V, Lisboa, Fundação Calouste Gulbenkian, 1984, pp. 198-199.

42 A. Morales Muñiz e D. Carmen Morales Muñiz, "De quién es...", p. 395; J. V. Matellanes Merchán, "Aproximación a la...", p. 341.

43 J. Orlandis, "Sobre el concepto del delito en el derecho de la Alta Edad Media", Anuario de Historia del Derecho Español, 16 (1945), pp. 112-192.

44 Entenda-se por pena pecuniária toda a pena que "implique una disminución del patrimonio del condenado, bien en dinero (multa), bien en bienes (confiscación)." Em M. P. Alonso Romero, "Aproximación al estudio de las penas pecuniarias en Castilla (siglos XIII-XVIII)", Anuario de Historia del Derecho Español, 55 (1985), p. 10. 
contribuindo, desta forma, para o enriquecimento dos cofres régios ou municipais. As penas pecuniárias tinham, por outro lado, a função de dissuadir as pessoas a voltarem a cometer as mesmas transgressões, castigando-as do ponto de vista financeiro.

Ligada a esta punição, encontrava-se uma sentença de caráter fiscal: o confisco de bens, com o fim de afetar o património do autor do delito ${ }^{45}$. Assim deveria acontecer, como, por exemplo, com a retenção de armadilhas e de outros artifícios usados na caça de perdizes, de codornizes, de rolas e de outros animais nas coutadas, conforme as diretrizes encontradas nos diplomas das chancelarias régias emitidos, sobretudo, durante o século $\mathrm{XV}$. A prisão era também outra pena prevista, devendo os criminosos ser entregues às autoridades judiciais, com a finalidade de os obrigar a pagar as multas impostas. Digamos que a privação da liberdade tinha uma dupla função, como pena e, como mecanismo de coação para os criminosos procederem ao pagamento das penas pecuniárias que tivessem em dívida. Já na segunda metade do século XV, podemos encontrar alusões a uma nova penalização na documentação régia, -o degredo para o norte de África (Arzila, por exemplo)-, cuja permanência no lugar de desterro variava consoante a categoria social do criminoso. Posto de outro modo, se fosse um escudeiro o degredo era de um ano, ao passo que se tratasse de um peão, este estaria afastado da sua terra durante dois anos ${ }^{46}$.

A par destas molduras penais, encontramos algumas medidas preventivas essenciais para reprimir e minimizar as práticas que pudessem estar na origem de condutas delituosas e de transgressões. Através da análise da documentação jurídica (diplomas, normas e outros regulamentos locais), uma das medidas encontradas consistia na vigilância e no "policiamento" das áreas coutadas, dos montes e das florestas, levados a cabo por funcionários régios ou municipais especializados, tais como os monteiros-mores, os couteiros-mores, entre outros. Estes estavam encarregados de cuidar e guardar os bosques e as coutadas, ao mesmo tempo, que deviam proceder ao controlo das atividades cinegéticas, piscícolas e silvícolas. Para isso, dispunham da ajuda de outros vigias, como, por exemplo, os caçadores, os couteiros, os monteiros a cavalo e os moços do monte, repartidos por zonas e de forma permanente. Em troca, estes funcionários dispunham de privilégios. Sendo assim, para Ihes facilitar os trabalhos de vigilância, usufruíam de licença para andar com as suas armas durante o dia e a noite, por questões de segurança e de zelo ${ }^{47}$. Como privilégio pelo exercício das suas funções, as suas armas não podiam ser penhoradas e confiscadas sob qualquer pretexto, devendo assim acontecer, a modo de exemplo, com os monteiros e os guardas das matas régias da Ota, segundo o diploma régio emitido a 14 de outubro de $1434^{48}$.

A prevenção não só era da responsabilidade régia ou concelhia, mas também dos donos das propriedades agrícolas. Estes últimos eram obrigados a cercar e a vedar as suas herdades para impedir a entrada de animais, pastores e caçadores, sob pena do pagamento de multas, como deveria acontecer nas vilas de Riba-Côa, Santarém e Beja, de acordo com os seus costumes e foros (século XIII) ${ }^{49}$. Coutar as propriedades, principalmente, as que se

45 M. Pino Abad, La pena de confiscación de bienes en el derecho histórico español, Córdoba, Servicio de Publicaciones de la Universidad de Córdoba, 1999, p. 135.

46 História Florestal, Aquícola e..., p. 69.

47 Ibídem, pp. 104-107.

48 História Florestal, Aquícola e..., vol. I, Lisboa, Ministério da Agricultura e Pescas. Direção-Geral do Ordenamento e Gestão do Território, 1983, pp. 262-263.

49 "Costumes e Foros de Beja", Portvgaliae Monumenta Histórica..., vol. II, pp. 69-70, Título [215]; "Costumes e Foros de Santarém", Portvgaliae Monumenta Histórica..., vol. I, p. 32, Título. [164]; Z. Brandão, Monumentos e Lendas de Santarém, Lisboa, David Corazzi-Editor, 1883, p. 397, Título 184; "Costumes e foros de Borba", 
localizavam próximo das cidades e das vilas era uma alternativa promulgada na legislação régia, como deveria acontecer, por exemplo, com as lezírias de Santarém, localizadas no rio Tejo, segundo a carta régia de confirmação de coutada, outorgada a 16 de julho de $1487^{50}$.

Com o objetivo de reforçar a manutenção e a preservação destes empreendimentos, é possível encontrar nos códigos costumeiros ribacoanos uma norma que consistia em punir todos aqueles que destruíssem as vedações das propriedades agrárias, sem esquecer os incidentes resultantes da passagem de animais ${ }^{51}$.

Apesar destes esforços enunciados nos regulamentos locais e nos diplomas das chancelarias régias, sublinhamos que estas medidas não sortiram os efeitos esperados. Se assim não fosse, não teríamos acesso a uma constante promulgação de normas e de leis com conteúdos semelhantes em fontes diferentes, ao longo de mais de trezentos anos. Também, não nos esqueçamos que estes problemas se prolongaram ao longo do século $\mathrm{XVI}$, como podemos constatar na documentação selecionada. Neste sentido, registamos, assim, uma clara continuidade nas problemáticas, nos perigos, nos acidentes e nos delitos que pautavam as relações entre as populações e as aves ao longo do período moderno, que nem sempre foram as mais tranquilas.

\section{CONCLUSÃO}

Em suma, estudar as relações entre as aves e as comunidades humanas pressupõe um reto para o investigador, uma vez que se trata de uma temática atual que aguarda um estudo mais minucioso e atento, sobretudo, numa perspetiva transdisciplinar ${ }^{52}$, indo mais além de alguns levantamentos e de coletâneas de documentação sobre as atividades cinegéticas, florestais e aquícolas. Além disso, torna-se não só pertinente conhecer as espécies de animais, neste caso as aves, nas mais diversas fontes (sejam elas de natureza económica, jurídica, cultural, literária, iconográfica, arqueozoológica e entre outras), mas também compreender as estratégias de organização dos recursos naturais e os conflitos que advinham da fauna ornitológica. Este tipo de análise remete-nos, porém, para um problema de carência e de dispersão de dados, levando-nos a um trabalho de recolha minuciosa e sistemática de informações em documentação tão diversificada, uma vez que são poucas as fontes específicas sobre as aves, como os tratados de cetraria, os "corpora" costumeiros, por exemplo. Estamos, portanto, defronte de informações que exigem uma visão global, abarcando diversas áreas do conhecimento para se proceder ao levantamento e ao tratamento das mesmas. Por outro lado, convém sublinhar que podemos encontrar, ainda que de forma indireta, muitas referências às aves, associadas aos mais variados aspetos do dia-a-dia das populações, em diferentes tipos de documentação. Neste sentido, destacamos ainda a importância do binómio documentação e fontes zooarqueológicas, uma vez que nos proporciona resultados mais amplos, levando-nos a colocar em cima da mesa

M. C. Matias Rodrigues, Dos Costumes de Santarém. Dissertação de Mestrado em Linguística Portuguesa Histórica apesentada à Faculdade de Letras da Universidade de Lisboa, 1992. Exemplar Policopiado, pp. 146-147, Título [164].

50 História Florestal, Aquícola e..., pp. 107-108.

51 "Costumes e Foros de Castelo Melhor", Portvgaliae Monumenta Histórica..., p. 917, Título [172], Livro 5; "Costumes e Foros Castelo Rodrigo", Portvgaliae Monumenta Histórica..., p. 872, Título [185], Livro 5; "Costumes e Foros de Castelo Bom", Portvgaliae Monumenta Histórica..., p. 756, Título [97]; "Costumes e Foros de Alfaiates", Portvgaliae Monumenta Histórica..., p. 830, Título [100].

52 D. C. Morales Muñiz, "Zoohistoria. Reflexiones acerca de una nueva disciplina auxiliar de la ciencia histórica", Espacio, Tiempo y Forma. Serie III. Historia Medieval, 4 (1991), pp. 367-383. 
e a equacionar otras hipóteses sobre a ornitofauna, as caraterísticas físicas, a evolução das aves e a "correcta identificación biológica a la que se refieren los textos". ${ }^{53}$

Com este estudo podemos concluir que as populações mediévicas e dos primórdios do período moderno mantiveram uma estreita relação com as aves. Estes animais tiveram um papel fundamental na vida quotidiana das comunidades rurais e urbanas, que ia mais além das necessidades de abastecimento e de consumo. As aves eram também animais a ser preservados não só numa perspetiva económica de gestão e salvaguarda dos recursos naturais, bem como ambiental, no sentido de proteger e apostar numa exploração sustentável dos recursos naturais, mantendo, claro está, as reservas quanto ao uso deste conceito atual, sem querer cair em situações de anacronismo. Através da documentação compulsada (instrumentos jurídicos régios e locais) e dos livros de viagens sobre os arquipélagos portugueses, Madeira e Açores, podemos facilmente depreender que as populações tinham uma nítida consciência da necessidade de salvaguardar e de cuidar os seus animais, mais em concreto, as aves. Em contrapartida, as pessoas deviam assumir a responsabilidade judicial pelos prejuízos e acidentes que as aves provocassem, segundo os preceitos legais, sobretudo em defesa dos bens privados ou públicos para minimizar os atritos que pudessem surgir. Desta forma, pretendeu-se determinar, por um lado, os conflitos ocasionados entre as comunidades humanas e a fauna ornitológica e avaliar, por outro lado, como as sociedades se defrontaram diante deste tipo de vicissitudes. 